suggest a 5 year survival rate of $16 \%$ in cases treated surgically. Perhaps because of its rarity, prognostic factors are difficult to discern; it appears not to depend on either clinical stage or histologic grade. ${ }^{8}$ Adrenocortical cancer shares with renal cell carcinoma the unusual propensity to propagate tumour thrombus along major veins, as demonstrated in the current case. One might imagine that this feature should adversely affect prognosis, and our patient's 30 month recurrence-free interval is striking in this regard.

This case serves to point out that gynaecomastia may occasionally be due to hormonally active neoplasia. Other causes include trophoblastic tumours secreting human chorionic gonadotrophin (teratomas and some seminomas) and rare entities such as Leydig cell tumours ${ }^{11}$ and pelvic sarcomas. ${ }^{3}$ Perhaps all young men with gynaecomastia ought to have a steroid screen.

\title{
References
}

1. MacFarlane, D.A. Cancer of the adrenal cortex. Ann Roy Coll Surg Engl 1958, 23: 155-186.

2. Carlson, H.E. Current concepts: gynecomastia. $N$ Engl J Med 1980, 303: 795-799.

3. Herr, H.W., Hennessy, W.T. \& Kantor, A. Pelvic sarcoma causing gynecomastia. J Urol 1990, 143: 1008-1009.

4. Brotherton, J. \& Rothbart, B. Serum cortisol in adrenal hirsutism as estimated by 5 different methods. J Steroid Biochem 1990, 36, 641-649.

5. Limone, P., Molinatti, P., Merlini, C. \& Molinatti, G.M Gynaecomastia and azoospermia as sole presenting symptoms of feminizing adrenal tumour. Panminerva Med 1989 31: $83-87$.

6. Gabrilove, J.L., Sharma, D.C., Wotiz, H.H. \& Dorfman, R.I Feminizing adrenocortical tumors in the male: a review of 52 cases, including a case report. Medicine 1965, 44: 37-76.

7. Meagher, A.P., Hugh, T.B., Casey, J.H., Chisholm, D.J., Farrell, J.C. \& Yeates, M. Primary adrenal tumours - a ten-year experience. Aust NZ J Med 1988, 58: 457-462.

8. Bertagna, C. \& Orth, D.N. Clinical and laboratory findings and results of therapy in 58 patients with adrenocortical tumors admitted to a single medical center 1951-1978. Am J Med 1981, 71: 855-875.

9. Comite, F., Schiebinger, R.J., Albertson, B.D. et al. Isosexual precocious pseudopuberty secondary to a feminizing adrenal tumor. J Clin Endocrin Metab 1984, 58, 435-440.

10. Henley, D.J., van Heerden, J.A., Grant, C.S. \& Carpenter, P.C. Adrenal cortical carcinoma - a continuing challenge. Surgery 1983, 94: 926-931.

11. Haas, G.P., Pittaluga, S., Gomella, L. et al. Clinically occult Leydig cell tumor presenting with gynecomastia.J Urol 1989, 142: $1325-1327$.

Postgrad Med J (1993) 69, $483-485$

\section{Hypercalcaemia and multiple osteolytic lesions in childhood acute lymphoblastic leukaemia}

\author{
P.N. Soni
}

\author{
Department of Medicine, University of Natal and King Edward VIII Hospital, PO Box 17039, Congella, \\ 4013 Durban, Republic of South Africa
}

\begin{abstract}
Summary: A 12 year old boy presenting with hypercalcaemia (calcium $3.25 \mathrm{mmol} / \mathrm{l}$ ) and osteopaenia with multiple osteolytic lesions was found to have acute lymphoblastic leukaemia without lymphadenopathy or organomegaly. Hypercalcaemia is a rare feature of acute leukaemia, but the patients previously described all show very similar characteristics, which were highlighted in this patient. These include age (10-20 years), severe osteolytic bone lesions, lymphoblastic leukaemia, and normal white cell count with absent or rare circulating blasts. Parathyroid hormone levels were normal in this patient, and response to induction therapy was good. This case demonstrates that acute lymphoblastic leukaemia may present in an atypical form without peripheral blasts but with hypercalcaemia and gross skeletal changes.
\end{abstract}

\section{Introduction}

Hypercalcaemia and severe osteolytic lesions are rare complications of acute lymphoblastic leukae-

Correspondence: P.N. Soni, F.C.P.(S.A.)

Accepted: 2 November 1992 mia (ALL), and only a few cases with these presenting features have been recorded. ${ }^{1-5}$ This low incidence contrasts with the high incidence in some other lymphoid malignancies, such as myelomatosis and adult $\mathrm{T}$ cell leukaemia/lymphoma (ATLL). 
Radiographic bone changes occur in $21 \%$ of childhood cases of leukaemia at diagnosis. ${ }^{6}$ These include prominent transverse metaphyseal bands, intramedullary osteolytic mottling and periosteal reactions.

The presence of radiographic bone changes at diagnosis in patients with ALL does not appear to correlate with prognosis. ${ }^{6}$ The case history of a 12 year old boy presenting with hypercalcaemia and multiple osteolytic lesions due to ALL is reported.

\section{Case report}

A 12 year old boy was referred from a peripheral hospital with a problem of hypercalcaemia (3.25 $\mathrm{mmol} / \mathrm{l}$ ) and inability to walk. He complained of backache followed by a gradual onset of weakness of his lower limbs for 4 months progressing to inability to walk during the past month. The patient admitted to polydipsia, polyuria and vague abdominal pain.

On examination he was mildly dehydrated; there was no lymphadenopathy, hepatomegaly or splenomagaly. Neurological examination revealed proximal muscle weakness only. His blood count showed a haemoglobin concentration of $10.4 \mathrm{~g} / \mathrm{dl}$, a white cell count of $9.4 \times 10^{9} / 1$ with a normal differential white cell count and absence of blasts in the peripheral smear, and platelets of $335 \times 10^{9} / 1$. Electrolyte measurement showed a sodium of $143 \mathrm{mmol} / \mathrm{l}$, potassium $3.57 \mathrm{mmol} / 1$, urea 8.4 $\mathrm{mmol} / \mathrm{l}$ and creatinine $69 \mu \mathrm{mol} / \mathrm{l}$. Hypercalcaemia was confirmed $(3.25 \mathrm{mmol} / \mathrm{l})$ and the phosphate was normal $(1.32 \mathrm{mmol} / \mathrm{l})$; serum albumin was $35 \mathrm{~g} / \mathrm{l}$. The parathyroid hormone level (midmolecule) was 69 pmol/1 (normal 29-85 pmol/l).

Radiographic examination showed marked osteopaenia of the thoracic and lumbar vertebrae together with collapse of the upper thoracolumbar vertebral bodies (Figure 1). Osteolytic lesions were visible in both humeri (Figure 2), the skull and the necks of both femurs. No mediastinal masses were seen on the chest X-ray. Abdominal ultrasonography was normal.

The patient was treated initially with a saline infusion and frusemide, resulting in a lowering of the serum calcium to normal values and an improvement of the symptoms. Bone marrow examination showed an infiltrate of blasts of lymphoblastic origin. Cell marker studies were unhelpful. The patient was treated with prednisolone, vincristine, cytosine arabinoside and doxorubicin. He became ambulant subsequent to this induction chemotherapy. A remission was achieved after which he received cranial irradiation and intrathecal methotrexate. The patient remained well and was transferred to his hospital of origin. At no time during the patient's illness were blast

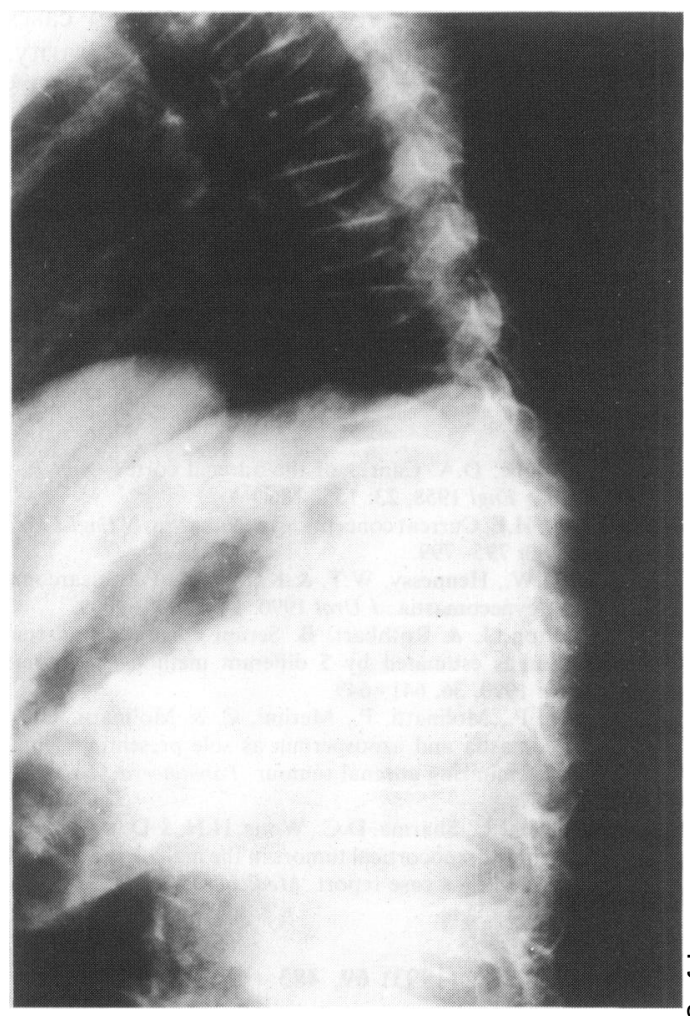

Figure $1 \mathrm{X}$-rays of the thoracolumbar vertebrae showing marked osteopaenia and collapse of vertebral bodies.

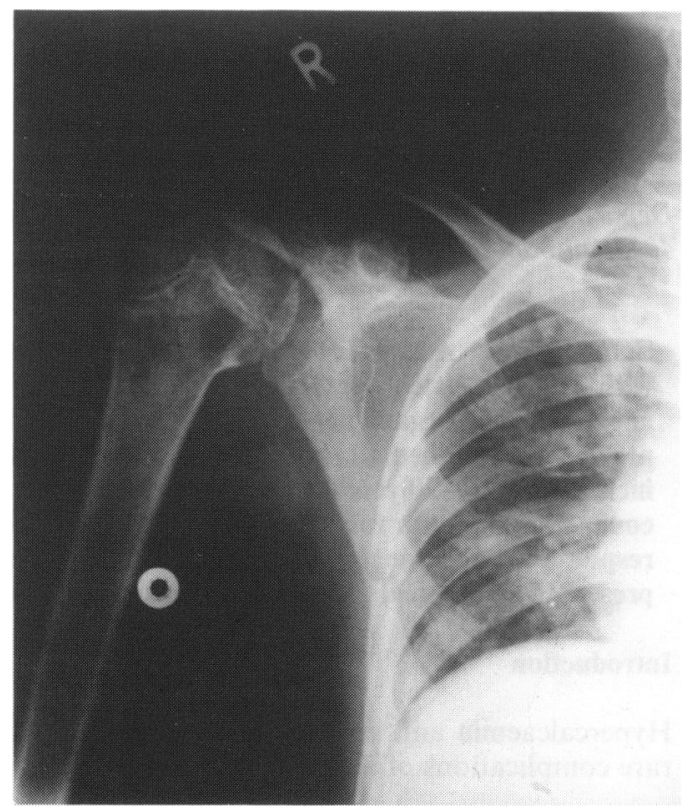

Figure 2 Osteolytic lesion in the proximal end of the humerus. 
cells seen in the peripheral smear. Bone lesions did not regress after chemotherapy, although the serum calcium level remained normal.

\section{Discussion}

This patient showed several unusual features for ALL. These include the presentation with hypercalcaemia, the normal white cell count, the absence of blasts in the peripheral smear, the absence of lymphadenopathy or organomegaly, and the presence of osteolytic lesions. Although fewer than 20 cases of ALL and hypercalcaemia have been reported, many show strikingly similar features to those described in this patient, namely, age 10-20 years, severe osteolytic lesions, and normal white cell count with rare or absent circulating blasts.

Myers, in 1956, ${ }^{1}$ included one case of acute leukaemia in a review of 61 patients with hypercalcaemia. This was the first record of the association of hypercalcaemia with leukaemia. In a series of 123 cases of leukaemia in which serum calcium and phosphorus were measured, $2.5 \%$ were found to have hypercalcaemia. ${ }^{4}$ Elevated calcium levels have also been reported in other malignancies in the absence of radiological or autopsy evidence of bone destruction. $^{\text {? }}$

Kalayjian et al. ${ }^{8}$ found that $96 \%$ of patients with leukaemia and radiological evidence of bone involvement were of the lymphoid type; furthermore, in over $50 \%$ the disease was of the leucopaenic variety. Griffiths ${ }^{9}$ has emphasized the association of bone changes with the 'aleukaemic' forms of acute leukaemia in children, resembling this case.

\section{References}

1. Myers, W.P.L. Symposium on medical aspects of cancer: clinical aspects and management of hypercalcaemia. Med Clin N America 1956, 40: 871-885.

2. Laffan, M.A., Talavera, J.G. \& Catovsky, D. Hypercalcaemia in T cell acute lymphoblastic leukaemia: report of two cases. J Clin Path 1986, 39: 1143-1146.

3. Harguindey, S., De Castro, L., Barcos, M., Getas, E.P., Henderson, E.S. \& Freeman, A. Hypercalcaemia complicating childhood malignancies. Cancer 1979, 44: 2280-2290.

4. Jordan, G.W. Serum calcium and phosphorous abnormalities in leukaemia. Am J Med 1966, 41: 381-390.

5. Moncrieff, M.W., Emerson, P.M., Windebank, K.P. \& Shepherd, L.E. Acute lymphoblastic leukaemia presenting with hypercalcaemia. Clin Lab Haematol 1985, 7: 271-273.

6. Aur, R.J., Westbrook, H.W. \& Riggs, W. Childhood acute lymphocytic leukaemia. Initial radiological bone involvement and prognosis. Am J Dis Child 1972, 124: 653-654.
Cell markers were not helpful in our patient; however, a recent report has shown two cases with T-ALL, hypercalcaemia and osteolytic lesions. ${ }^{2}$ Another case was CALLA (common-ALL antigen)-positive. ${ }^{5}$

Some investigators suggest that there is no significant relationship between initial bone involvement and clinical outcome in childhood ALL. ${ }^{6}$ Others have reported a much shorter duration of remission in patients with ALL and bone lesions on radiographs. ${ }^{10}$ None of these studies has prospectively assessed whether growth is affected by the bone lesions, or whether radiological healing of lesions occurred with chemotherapy.

In most cases no mechanisms for the hypercalcaemia has been found, although one previous case has demonstrated a raised concentration of vitamin $\mathrm{D} 3,{ }^{2}$ and one reported autonomous production of parathyroid hormone by lymphoblastic leukaemia cells in culture. ${ }^{11}$ This patient had a normal level of parathyroid hormone, although one would expect this to be suppressed. Production of an osteoclast activating factor or factors would seem the most likely explanation for most cases of hypercalcaemia in lymphoblastic lymphoma. ${ }^{12}$

This case illustrates that lymphoblastic leukaemia must be considered in the differential diagnosis in a young patient presenting with hypercalcaemia, even when there are no peripheral blast cells.

\section{Acknowledgements}

I would like to thank Dr V. Gathiram for constructive comments on the manuscript.

7. Plimpton, C.H. \& Gellhorn, A. Hypercalcaemia in malignant disease without evidence of bone destruction. $\mathrm{Am} \mathrm{J} \mathrm{Med}$ 1956, 21: 750-759.

8. Kalayjian, B.S., Herbut, P.A. \& Erf, L.A. The bone changes of leukaemia in children. Radiology 1946, 47: 223-233.

9. Griffiths, D.L. Modern Trends in Blood Diseases. J.F. Wilkinson, London, 1955.

10. Masera, G., Carnelli, V., Ferrari, M., Recchia, M. \& Bellini, F. Prognostic significance of radiological bone involvement in childhood acute lymphoblastic leukaemia. Arch Dis Child 1977, 52: 530-533.

11. Ramsay, N.K.S., Brown, D.M., Nesbit, M.E., Coccia, P.F., Krivit, W. \& Krutzik, S. Autonomous production of parathyroid hormone by lymphoblastic leukaemia cells in culture. J Paediatr 1979, 94: 623-625.

12. Cohn, S.L., Morgan, E.R. \& Mallette, L.E. The spectrum of metabolic bone disease in lymphoblastic leukaemia. Cancer 1987, 59: 346-350. 